\title{
вмј Global Health Priority setting during the COVID-19 pandemic: going beyond vaccines
}

lestyn Williams, ${ }^{1}$ Beverley Essue, ${ }^{2}$ Elysee Nouvet, ${ }^{3}$ Lars Sandman, ${ }^{4}$ S Donya Razavi (10 , ${ }^{5}$ Mariam Noorulhuda, ${ }^{6}$ Susan Goold, ${ }^{7}$ Marion Danis, ${ }^{6}$ Godfrey Biemba, ${ }^{8}$ Julia Abelson, ${ }^{9}$ Lydia Kapiriri (1) ${ }^{5}$

To cite: Williams I, Essue B, Nouvet $\mathrm{E}$, et al. Priority setting during the COVID-19 pandemic: going beyond vaccines. BMJ Global Health 2021;6:e004686. doi:10.1136/ bmjgh-2020-004686

Received 7 December 2020 Revised 10 December 2020 Accepted 15 December 2020
Check for updates

(C) Author(s) (or their employer(s)) 2021. Re-use permitted under CC BY. Published by BMJ.

For numbered affiliations see end of article.

Correspondence to Dr Lydia Kapiriri;

kapirir@mcmaster.ca

\section{INTRODUCTION}

Successful vaccination against the SARS-CoV-2 virus is a decisive development in the international response to the pandemic. It also has substantial implications for how governments and international bodies deploy their resources, as major decisions will need to be made in a fast-moving and uncertain environment. Current trends in vaccine development have stimulated much commentary on how vaccines deemed to be the safest and most effective should be allocated, both at the global level (to ensure access for lowincome countries) $)^{12}$ and within countries (to prioritise critical personnel and the most vulnerable population groups). ${ }^{3}$ We recognise the importance of mass vaccination as a public health measure, and the crucial need to promote equity and solidarity across countries. ${ }^{45}$ We also recognise that prioritisation is required within countries so that resources are directed to best protect life, reduce inequities and increase public confidence. However, based on analysis of the COVID-19 response so far, we would argue that at least three additional forms of prioritisation are required: between vaccines; between vaccines and other elements of the pandemic response; and between COVID-19 and other areas of health provision. In each case, decision makers should concentrate as much on infrastructure and implementation as on principles of resource allocation.

\section{SELECTING VACCINES: THE LONG TERM}

As we have already seen, there is a temptation for governments to invest most of their available resources in the vaccines exhibiting the greatest promise of efficacy and safety. However, there are many alternative vaccines currently undergoing phase III clinical trials. If the objective is to reduce the global burden of COVID-19 in the long term and avoid
Summary box

Development of vaccines is a major breakthrough in the fight against the SARS-CoV-2 virus.

- Much attention has been paid to how to prioritise between patient groups for vaccination and how to ensure equity, especially in low-income countries, but there are other important decisions that need to be made.

- These decisions include: (a) choosing between the various vaccines that will become available, (b) continuing to invest in other aspects of the COVID-19 response and (c) balancing the COVID-19 response with the need to invest in other healthcare that has suffered during the pandemic.

- Although these decisions are inherently difficult, principles of good priority setting can be helpful; these principles include: evidence-based and transparent decision-making, participation of stakeholders and a focus on the implementation of decisions.

deepening inequities in the process, both vaccine cost-effectiveness and equity must be considered.

Asssessing cost-effectiveness between vaccines is hampered by their independent development and evaluation to date. Headto-head comparisons may be further compromised by the need to account for variations in effectiveness and their ability to protect different subpopulations. Ultimately, implementation costs are likely to prove to be as, if not more, important than narrow costeffectiveness profiles in determining which options are best suited in any given context. Cost analysis should therefore encompass logistical and distribution issues, which are likely to be significant drivers of affordability and influenced by, for example, the requirement for vaccine storage at very low temperatures. ${ }^{6}$

Vaccine costs and cost-effectiveness should be considered in the wider context of equity of access and outcome, and fair allocation 
of resources within and across populations. ${ }^{78}$ Though COVID-19 vaccines may initially be funded by donors, all countries will need long-term, mass COVID-19 vaccination strategies to ensure equitable and sustainable practices. Circumstances in which access is dependent on out-of-pocket contributions, or where available vaccines are perceived as unsafe and/or ineffective, will fuel inequity, antivaccine propaganda, and black and grey vaccine markets. $^{9}$

\section{PRIORITISING ACROSS THE COVID-19 RESPONSE}

The experience of COVID-19 so far has been marked by variation in system responses and notable resource shortages for both public health and treatment measures. ${ }^{10}$ The cost of investing in mass vaccination should therefore be weighed against the continued need for these other public health and treatment measures, as the vaccine will not immediately eradicate the virus. Embedding vaccination programmes in a well-resourced overall pandemic strategy and infrastructure will help with roll-out. Contact tracing, protective equipment, treatment and environmental mitigation strategies such as indoor ventilation will all still be required, although in (hopefully) reducing orders of magnitude. These tools will continue to play a critical role in the pandemic response in contexts where vaccines are not available for whole populations at once, or vaccine effectiveness diminishes. Recent reports of virus mutations in mink in Denmark and other countries and its potential spread to humans highlight the importance of ongoing vigilance and public health investment across the COVID-19 response. ${ }^{11}$

\section{PRIORITISING ACROSS HEALTHCARE PROGRAMMES}

An accompanying feature of the pandemic has been the suspension of many areas of routine care, including vaccination for preventable diseases. ${ }^{12} 13$ The ramifications of this will have to be dealt with not only in the months ahead but for many years to come. Backlogs and capacity constraints will result in excess mortality attributable to COVID-19-already modelled for several disease areas such as cancer ${ }^{14} 15$ and cardiovascular disease. ${ }^{16} 17$ Catching up on backlogs will place additional, competing demands on the resources available. Investment in vaccination will need to account for this 'suspended care need' and should be weighed against the immediate and longer term requirements for the delivery of routine health programmes.

In lower income countries (LICs), the consequences are especially stark, with lives lost due to a lack of routine urgent care through unemployment, restrictions on movement and healthcare, as well as a wider reluctance to attend healthcare facilities due to fears of contracting COVID-19. Furthermore, previous health emergencies, such as the most recent Ebola outbreak in West Africa, have shown a decline in funding for other essential programmes such as child and maternal health services. ${ }^{18}$ The impact of further diverting scarce resources away from other areas of need will therefore need to be closely monitored and evaluated in order to understand the potential consequences of placing a higher value on one life saved from COVID-19 over one life saved from other conditions.

\section{FOCUS ON IMPLEMENTATION}

Our analysis of COVID-19 international pandemic responses highlights the critical importance of planning for effective implementation of any mass vaccination programme. ${ }^{19}$ If the global community is seriously committed to a fair and just international COVID-19 vaccination strategy, the conversation must go beyond mitigating inequities in nations' purchasing power and access to safe and effective vaccines. There are additional inequities across and within countries in terms of the resources available for mobilisation and infrastructure in place to support a mass vaccination campaign. ${ }^{20}$ Meanwhile, the burden on agencies at the forefront of the COVID-19 response cannot be overstated. Vaccine roll-out, however welcome, is an additional strain not only in LICs but also increasingly in high-income countries. $^{21}{ }^{22}$ There is a need to support health systems to sustain routine services-this is more critical for weaker health systems seeking to prevent excessive avoidable mortality. ${ }^{20}$ Lastly, as countries plan to roll out COVID-19 vaccination, it is important that effective strategies to deal with vaccine hesitancy are developed and implemented. ${ }^{23} 24$

\section{CONCLUSIONS}

The fundamental tenets of good priority setting include: taking an explicit approach to decision-making; meaningful stakeholder engagement; consideration of public values, ensuring mechanisms for appeals and revisions; and use of relevant evidence. ${ }^{2526}$ Furthermore, for priority setting to be impactful, resource allocation should be aligned with set priorities. ${ }^{25}{ }^{27}$ In the case of vaccination against COVID-19, such tenets will be crucial, as mismanaged priority setting would have disastrous consequences for health, equity and trust in public health and policymakers. However, the challenges extend beyond choosing which patient groups to prioritise, and there is a risk that a narrow focus on such questions will distract from other choices that need to be made.

When selecting between vaccines for investment, governments should balance the requirement for urgency with the importance of ongoing evidenceinformed decision-making, as more becomes known about vaccine characteristics, adverse effects, duration of immunity and extent of protection from transmission. In evaluating vaccine options, decision makers should go beyond narrow cost-effectiveness profiling to assess implementation costs, especially those that are likely to vary across vaccines. Taking a 'real world' approach to priority setting requires decision makers to accept uncertainty with respect to the unfolding context, and 
conflicting ethical imperatives both in policy and wider society. There are no simple decision rules that can be transferred across contexts ${ }^{28}$ and consistency will best be served by the building of 'case law' as a means to inform, defend and refine decisions, and enable constant and careful monitoring and evaluation to ensure the greatest impact. ${ }^{29}$

In these conditions of uncertainty and occasional conflict, the design of vaccination programmes cannot be a purely technical task, and hence, there is a need for greater participation in decision-making than has been exercised so far with, for example, poor gender and racial representation on COVID-19 planning task forces. ${ }^{30}$ Successful vaccination programmes will require buy-in from patient groups, local implementers and healthcare professionals (including the largely unpaid community health workers who will be relied on to support vaccination programmes in LICs), as well as major players from industry and global donors. Most crucially, investment in COVID-19 vaccination should not be pursued at the expense of ongoing public health prevention and other health needs.

Health equity as an over-riding aim of the global COVID-19 response requires that priority setting goes beyond decision-making for vaccines and takes a more holistic view that also considers the challenges associated with the long-term effects of vaccine selection, priority setting across COVID-19 response and healthcare programmes as well as implementation.

\section{Author affiliations \\ ${ }^{1}$ Health Services Management Centre, University of Birmingham, Birmingham, UK ${ }^{2}$ Institute of Health Policy, Management and Evaluation, University of Toronto, Toronto, Ontario, Canada \\ ${ }^{3}$ School of Health Studies, Western University, London, Ontario, Canada ${ }^{4}$ Department of Health, Medicine and Caring Sciences, Linköping University, Linkoping, Sweden \\ ${ }^{5}$ Department of Health, Aging and Society, McMaster University, Hamilton, Ontario, Canada \\ ${ }^{6}$ Department of Bioethics, National Institutes of Health, Bethesda, Maryland, USA ${ }^{7}$ Center for Bioethics and Social Sciences in Medicine, University of Michigan, Ann Arbor, Michigan, USA \\ ${ }^{8}$ National Health Research Authority and Public Health, Lusaka Apex Medical University, Lusaka, Zambia \\ ${ }^{9}$ Health Research Methods, Evidence and Impact, McMaster University, Hamilton, Ontario, Canada}

Twitter lestyn Williams @lestynPWilliams and S Donya Razavi @donya_razavi

Contributors IW introduced the idea. All authors contributed to the development, editing and finalising the manuscript.

Funding The project is funded by the McMaster COVID-19 fund.Danis M. was funded by the intramural program at the US National Institutes of Health.

Disclaimer The funders were not in any way involved in the development of this paper.The views expressed here are those of the authors and not necessarily a reflection of the policies of their employers.

Competing interests None declared.

Patient consent for publication Not required.

Provenance and peer review Not commissioned; externally peer reviewed.

Data availability statement There are no data in this work.

Open access This is an open access article distributed in accordance with the Creative Commons Attribution 4.0 Unported (CC BY 4.0) license, which permits others to copy, redistribute, remix, transform and build upon this work for any purpose, provided the original work is properly cited, a link to the licence is given, and indication of whether changes were made. See: https://creativecommons.org/ licenses/by/4.0/.

\section{ORCID iDs}

S Donya Razavi http://orcid.org/0000-0002-9501-4768

Lydia Kapiriri http://orcid.org/0000-0002-1237-6369

\section{REFERENCES}

1 Emanuel EJ, Persad G, Kern A, et al. An ethical framework for global vaccine allocation. Science 2020;369:1309-12 https://science. sciencemag.org/content/369/6509/1309

2 Liu Y, Salwi S, Drolet BC. Multivalue ethical framework for fair global allocation of a COVID-19 vaccine. J Med Ethics 2020;46:499-501.

3 Persad G, Peek ME, Emanuel EJ. Fairly prioritizing groups for access to COVID-19 vaccines. JAMA 2020;324:1601-2.

4 Bollyky T, Gostin LO, Hamburg MA. The equitable distribution of COVID-19 therapeutics and vaccines. JAMA - J Am Med Assoc 2020:E1-2.

5 Joint CCGHR-CSIH. JOINT CCGHR-CSIH STATEMENT AND CALL TO ACTION: DEFEATING COVID-19 CALLS FOR GLOBAL SOLIDARITY, NOT A VACCINE POWER PLAY [Internet]. Canadian Coalition for Global Health Research, 2020. Available: https://www. ccghr.ca/joint-ccghr-csih-statement-call-action-defeating-covid-19calls-global-solidarity-vaccine-power-play/ [Accessed cited 2020 Nov 21].

6 Ortiz JR, Robertson J, Hsu J-S, et al. The operational impact of deploying SARS-CoV-2 vaccines in countries of the who African region. medRxiv 2020.

7 Emanuel EJ, Persad G, Upshur R, et al. Fair allocation of scarce medical resources in the time of Covid-19. New Engl J Medircine 2020:1-7

8 Norheim OF, Baltussen R, Johri M, et al. Guidance on priority setting in health care (GPS-Health): the inclusion of equity criteria not captured by cost-effectiveness analysis. Cost Eff Resour Alloc 2014;12:18-8.

9 Bloomberg News. Covid Vaccine Rush in China Raises Fears of Booming Black Market [Internet]. BNN Bloomberg, 2020. Available: https://www.bnnbloomberg.ca/covid-vaccine-rush-in-china-raisesfears-of-booming-black-market-1.1527993 [Accessed cited 2020 Nov 27].

10 McMahon DE, Peters GA, Iversid LC, et al. Global resource shortages during covid-19: bad news for low-income countries. PLoS Negl Trop Dis [Internet] 2020;14:1-3.

11 Frutos R, Devaux CA. Mass culling of minks to protect the COVID-19 vaccines: is it rational? New Microbes and New Infections 2020;38:100816.

12 Matos CCdeSA, Barbieri CLA, Couto MT. Covid-19 and its impact on immunization programs: reflections from Brazil. Revista de Saúde Pública 2020;54:114 http://www.ncbi.nlm.nih.gov/pubmed/ 33175028

13 Nyasulu J, Pandya $\mathrm{H}$. The effects of coronavirus disease 2019 pandemic on the South African health system: a call to maintain essential health services. Afr J Prim Health Care Fam Med 2020;12:1-5.

14 Sud A, Torr B, Jones ME, et al. Effect of delays in the 2-weekwait cancer referral pathway during the COVID-19 pandemic on cancer survival in the UK: a modelling study. Lancet Oncol 2020;21:1035-44.

15 Maringe C, Spicer J, Morris M, et al. The impact of the COVID-19 pandemic on cancer deaths due to delays in diagnosis in England, UK: a national, population-based, modelling study. Lancet Oncol 2020;21:1023-34.

16 Brant LCC, Nascimento BR, Teixeira RA, et al. Excess of cardiovascular deaths during the COVID-19 pandemic in Brazilian capital cities. Heart 2020;106:1898-905.

17 Burda Z. Modelling excess mortality in covid-19-like epidemics. Entropy 2020;22:1236-21.

18 Delamou A, Ayadi AME, Sidibe S, et al. Effect of Ebola virus disease on maternal and child health services in guinea: a retrospective observational cohort study. The Lancet Global Health 2017;5:e448-57.

19 McMaster University. Lydia Kapiriri [Internet]. Faculty of Social Sciences, 2020. Available: https://socialsciences.mcmaster.ca/ people/kapiriri-lydia\#biography [Accessed cited 2020 Nov 27].

20 Wallace L, Kapiriri L. How are new vaccines prioritized in low-income countries? A case study of human papilloma virus vaccine and 
pneumococcal conjugate vaccine in Uganda. Int J Health Policy Manag 2017;6:707-20.

21 MacDonald NE, Comeau J, Dubé E, et al. A public health timeline to prepare for COVID-19 vaccines in Canada. Can J Public Health 2020;111:945-52.

22 Ranney ML, Griffeth V, Jha AK. Critical supply shortages - the need for ventilators and personal protective equipment during the Covid-19 pandemic. N Engl J Med 2020;382:e41-e41(3).

23 et alRatzan SC, Binagwaho A, Rabin K. COVID-19: A global survey shows worrying signs of vaccine hesitancy [Internet]. The Conversation, 2020. Available: https://theconversation.com/covid19-a-global-survey-shows-worrying-signs-of-vaccine-hesitancy148845 [Accessed cited 2020 Nov 24].

24 Lazarus JV, Ratzan SC, Palayew A, et al. A global survey of potential acceptance of a COVID-19 vaccine. Nat Med 2020;33.

25 Kapiriri L. International validation of quality indicators for evaluating priority setting in low income countries: process and key lessons. BMC Health Serv Res 2017;17:1-14.
26 Norheim OF. The elusive challenge of priority setting in health and health care. Global Challenges 2017;1:28-9.

27 Sibbald SL, Singer PA, Upshur R, et al. Priority setting: what constitutes success? A conceptual framework for successful priority setting. BMC Health Serv Res 2009;9:43 http://bmchealthservres. biomedcentral.com/articles/

28 Moodley K, Ravez L, Obasa AE, et al. What Could "Fair Allocation" during the Covid-19 Crisis Possibly Mean in Sub-Saharan Africa? Hastings Center Report 2020;50:33-5.

29 Daniels N, Sabin J. Limits to health care: fair procedures, Democratic deliberation, and the legitimacy problem for insurers. Philos Public Aff 1997;26:303-50.

30 van Daalen KR, Bajnoczki C, Chowdhury M, et al. Symptoms of a broken system: the gender gaps in COVID-19 decision-making. BMJ Glob Health 2020;5:e003549. 